\title{
Dielectric Relaxations in Poly( $\gamma$-n-alkyl L-glutamate)s I. Study of the Relaxations above Room Temperature Using the Direct-Current Technique
}

\author{
Maeko KaKIZAKI, Hirofumi NaKaYAma, Hiroyuki TANAKA, \\ and Teruo HIDESHIMA \\ Department of Applied Physics, Faculty of Engineering, \\ Hokkaido University, Sapporo 060, Japan
}

(Received March 22, 1985)

\begin{abstract}
Time and temperature dependences of the absorption and conduction currents in poly( $\gamma$ - $n$-alkyl L-glutamate)s, having methyl, ethyl, $n$-propyl, and $n$-butyl groups, have been investigated at temperatures ranging from -15 to $80^{\circ} \mathrm{C}$ and in the time range from 10 to $900 \mathrm{~s}$. The data on the DC current have been analyzed by the Hamon approximation and the method of reduced variables and converted into the loss permittivity master curves. The master curve is composed of the contribution from a relaxation and that from a conduction current. The former is a new relaxation named $\alpha$-relaxation and characterized by the relaxation spectrum whose shape is independent of the side-chain length and much sharper than that of the spectrum for the side-chain relaxation called $\beta$-relaxation. The shift factor is common to the $\alpha$-relaxation and conduction process, obeying the WLF equation with parameters proper to each sample. The glass transition temperature for each sample was determined as the temperature at which the shift factor deviates from the WLF equation. It decreases with an increase of the side-chain length, while the thermal expansion coefficient of the free volume fraction determined from the WLF parameters shows the opposite tendency. The nature of the dielectric $\alpha$-relaxation is discussed briefly.

KEY WORDS Dielectric Relaxation / Absorption Current / Conduction

Current / WLF Equation / Glass Transition / Poly $(\gamma$-methyl L-glutamate) /

Poly( $\gamma$-ethyl L-glutamate) / Poly( $\gamma$-n-propyl L-glutamate) / Poly( $\gamma$ - $n$-butyl Lglutamate) /
\end{abstract}

The relaxational behavior of $\operatorname{poly}(\gamma-n$-alkyl L-glutamate)s, (PnALG)s, in the solid state has been studied by mechanical and dielectric measurements in relation to morphology and molecular structure. ${ }^{1-8}$ Especially investigations of the mechanical relaxations between -180 and $250^{\circ} \mathrm{C}$ have revealed that there are at least three relaxation regions or loss bands. These are found to be below $-50^{\circ} \mathrm{C}$, around $0^{\circ} \mathrm{C}$, and above room temperature respectively when the measurements are made in the range of audiofrequencies. Similar results have been obtained for $\operatorname{poly}(\gamma$-methyl D-glutamate), PMDG. $^{9-13}$

The current interpretation for these relax- ations is that the relaxations appearing around $0^{\circ} \mathrm{C}$ and below $-50^{\circ} \mathrm{C}$ are caused by a motion of the side chain as a whole and a local motion in it respectively, while the relaxation above room temperature is caused by a motion of the main chain in a disordered state or forming an $\alpha$-helix. The change of morphology in different samples makes a variety of these relaxations and complicates the problem of identification.

On the other hand, dielectric studies of this series of polymers have shown that there are relaxations appearing around $0{ }^{\circ} \mathrm{C}$ and below $-50^{\circ} \mathrm{C}$ in accordance with the results given by the mechanical measurements. However, the 
dielectric relaxation at higher temperatures has scarcely been investigated. The aim of the present paper is to clarify the characteristics of the dielectric relaxation in (PnALG)s at higher temperatures in relation to the change of sidechain length.

For this purpose, the measurements at very low frequencies using the direct-current technique were carried out. This method has the following advantages: (1) the "high-temperature relaxation" can be observed at much lower temperatures than by the measurements using the audiofrequency technique and consequently the change in a quality of the samples during experiment can be avoided; (2) the other relaxation existing at lower frequencies can be well separated from the relaxation to be studied here; (3) the relation between the dielectric losses due to absorption and conduction currents can readily be investigated.

\section{EXPERIMENTAL}

\section{Samples}

Four samples of (PnALG)s were investigated in which the alkyl groups were methyl, ethyl, $n$-propyl, and $n$-butyl respectively. We shall designate them as PMLG, PELG, PnPLG and PnBLG hereafter. PMLG (Ajicoat A-2000) was supplied by Ajinomoto Co., Ltd. Other samples were made from PMLG by ester exchange reaction with appropriate alcohols. The proton NMR spectra for the samples thus obtained showed that the exchange reaction was nearly complete.

Films of the samples for the electric measurements were prepared from concentrated chloroform solutions by evaporating the solvent gradually on a glass plate at room temperature. The films were dried in vacuum for several weeks and then annealed at $c a$. $160^{\circ} \mathrm{C}$ for $24 \mathrm{~h}$. Infrared spectra of the films showed that the main chain conformation in these films was an $\alpha$-helix. Thickness of the films was in the range from 0.05 to $0.18 \mathrm{~mm}$.

\section{Measurements}

The direct current was measured with a vibrating-reed electrometer TR-84M made by Takeda Riken Industry Co. from 10 to $900 \mathrm{~s}$ after the application of a constant DC voltage. The measurement was made at temperatures ranging from $c a .-15^{\circ} \mathrm{C}$ to $c a .80^{\circ} \mathrm{C}$ at $c a .5^{\circ} \mathrm{C}$ intervals. Temperature was determined by a copper-constantan thermocouple placed near the sample and its fluctuations during the experiment were kept within $\pm 0.5^{\circ} \mathrm{C}$. The constant DC voltage was supplied by a DC voltage source GP $0160-1$ made by Takasago Manufacturing Co. A three-electrode arrangement made by Ando Electric Co. was used. The effective area of the main electrode was $c a$. $4.89 \mathrm{~cm}^{2}$.

Measurements were carried out from lower to higher temperatures. After measuring the charging current at each temperature, the sample was short-circuited while the temperature was raised for the next measurement. This procedure saved the time necessary for reducing the discharging current to the level of an experimental error before the next measurement. The linearity relation between the current and the voltage was checked at various temperatures and times. All the data given in this paper satisfied the condition of linearity.

\section{METHOD OF ANALYSIS}

The data on the DC current at a constant temperature seem to be composed of absorption and conduction currents which closely overlap each other. The determination of the conduction current is rather difficult and uncertain, because it is ambiguous whether the steady state is reached or not. In such a case the discharging current is often used to separate these two components by assuming that it is equivalent to the negative absorption current shifted on the time axis. However, it should be noted that, as in the case of the creep recovery in the mechanical relaxation, ${ }^{14}$ the 
discharging current is equivalent to the negative absorption current only after the absorption current has reached a stationary state. In the present case it is very difficult to discriminate whether such a condition is satisfied or not.

On the other hand, though the separation of the absorption current from the total observed current is difficult, a rough estimation suggests that the absorption current can be dealt with by the Hamon approximation. ${ }^{15}$ Therefore, we shall analyze the data as follows.

It is well-known that the current at time $t$ after the application of a stepwise voltage $V_{\mathrm{O}}$ is generally given by

$$
I(t)=G_{\mathrm{O}} V_{\mathrm{O}}+C_{\infty} V_{\mathrm{O}} \delta(t)+C_{\mathrm{v}} V_{\mathrm{O}} \phi(t)
$$

where $G_{\mathrm{O}}, C_{\infty}, C_{\mathrm{v}}$ and $\phi(t)$ are DC conductivity, instantaneous capacity, geometric capacity and decay function of the sample respectively and $\delta(t)$ is the $\delta$-function. The first, second and third terms on the right-hand side of eq 1 denote conduction, instantaneous charging and absorption currents respectively. When the thickness and the area of the sample are written as 1 and $S$,

$$
G_{0}=\sigma \frac{S}{1}=4 \pi C_{v} \sigma
$$

where $\sigma$ is the specific DC conductivity. From eq 1 and 2 it follows that

$$
\frac{t I(t)}{C_{v} V_{0}}=4 \pi \sigma t+t \phi(t)
$$

If $\phi(t)$ is represented by $A t^{-n},(0.3<n<1.2)$, it is well-known that loss permittivity at an angular frequency $\omega$ or frequency $f$ is related to the absorption current at a time $t$ by the Hamon approximation as

$$
\begin{aligned}
& \varepsilon_{r}^{\prime \prime}(\omega)=\frac{t \phi(t)}{0.63} \\
& t=0.63 / \omega \fallingdotseq 0.1 / f
\end{aligned}
$$

Consequently eq 3, 4 and 5 lead to the total loss permittivity composed of the conduction and relaxation components,

$$
\frac{t I(t)}{0.63 C_{v} V_{0}}=\frac{4 \pi \sigma t}{0.63}+\frac{t \phi(t)}{0.63}=\frac{4 \pi \sigma}{\omega}+\varepsilon_{r}^{\prime \prime}(\omega)=\varepsilon^{\prime \prime}(\omega)
$$

Generally $\varepsilon_{\mathrm{r}}{ }^{\prime \prime}(\omega)$ can be represented by introducing a dielectric relaxation spectrum $L_{\mathbf{D}}(\tau)$ as

$$
\varepsilon_{r}^{\prime \prime}(\omega)=\int_{-\infty}^{\infty} \frac{L_{\mathrm{D}}(\tau) \omega \tau}{1+\omega^{2} \tau^{2}} \mathrm{~d} \ln \tau
$$

As will be shown later, the data on $I(t)$ seem to be subject to the method of reduced variables. Therefore, we assume the time-temperature reducibility as

$$
L_{\mathrm{D}}(\tau, T)=c L_{\mathrm{D}}\left(\tau / a_{\mathrm{T}}, T_{\mathrm{O}}\right)
$$

and

$$
\sigma\left(T_{\mathrm{o}}\right) / \sigma(T)=c a_{\mathrm{T}}
$$

where $c$ and $a_{\mathrm{T}}$ are vertical and horizontal shift factors as functions of temperature $T$ and an arbitrary reference temperature $T_{\mathrm{O}}{ }^{14}$ If Walden's rule is applicable, namely if $\sigma$ is inversely proportional to viscosity, eq 9 can be derived from the time-temperature reduction of a mechanical relaxation spectrum. If eq 8 and 9 are valid, the reduction of the loss permittivity is given by the relation

$$
\varepsilon^{\prime \prime}(\omega, T)=c \varepsilon^{\prime \prime}\left(\omega a_{\mathrm{T}}, T_{\mathrm{O}}\right)
$$

\section{RESULTS AND DISCUSSION}

Figures $1,-4$ show the loss permittivity as a function of time or frequency for PMLG, PELG, PnPLG and PnBLG respectively, which were obtained from the data on the current using eq 6 . These figures clearly show that the loss caused by the dielectric relaxation predominates at lower temperatures while that caused by the DC conduction predominates at higher temperatures. We designate the relaxation as the $\alpha$-relaxation hereafter. A preliminary experiment showed that the relaxation usually attributed to the side-chain 


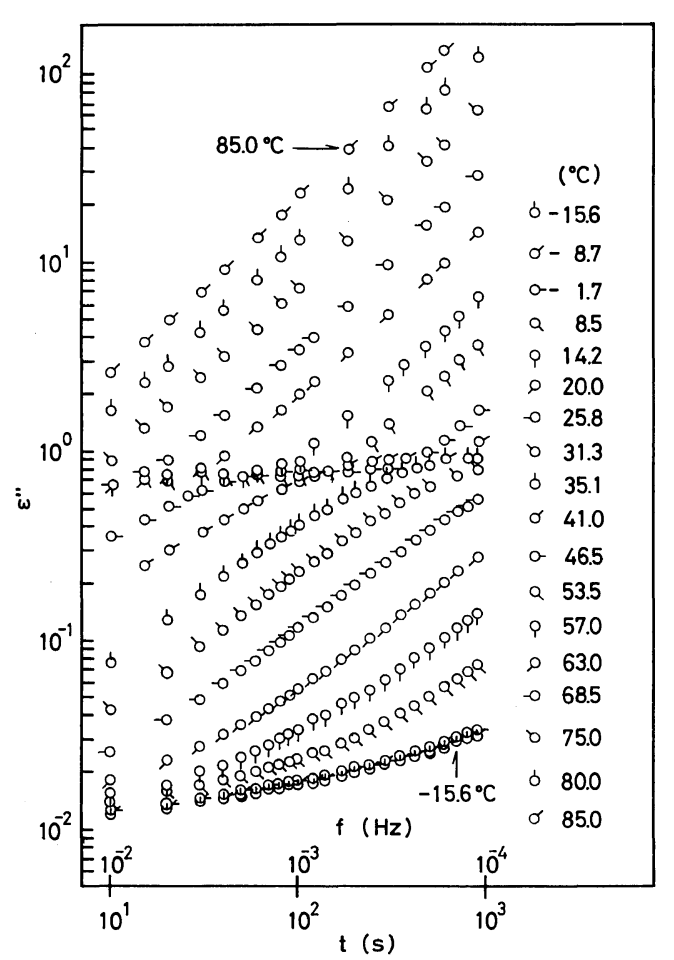

Figure 1. Time or frequency dependence of loss permittivity calculated from DC current data on PMLG at the temperatures indicated. Time, $t$, and frequency, $f$, are interrelated by the Hamon approximation, $t=0.1 / f$.

motion appeared at temperatures lower than those used here. It will be studied in a later paper.

Figures 5-8 show the master curves determined from these data. In Figure 8 several data points for the long time end of the master curve are omitted owing to lack of space. It should be noted that the reduction can be carried out using the horizontal shift alone. Therefore, the vertical shift factor is approximately equal to unity. Further, the horizontal shift could be made by a common shift factor over the whole temperature range as assumed in eq 8 and 9.

The horizontal shift factors for the four samples are plotted against temperature in Figures 9a, 9b, 9c, and 9d. The solid curves in these figures are calculated by the WLF equation, ${ }^{14} \log a_{\mathrm{T}}=-C_{1}\left(T-T_{\mathrm{o}}\right) /\left(C_{2}+T-T_{\mathrm{O}}\right)$,

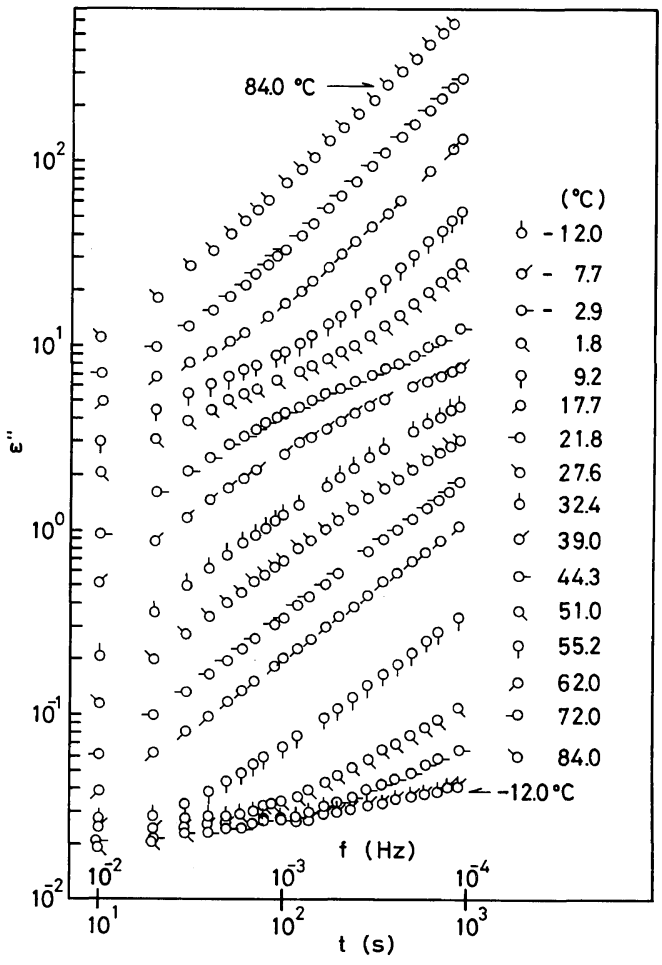

Figure 2. Time or frequency dependence of loss permittivity calculated from DC current data on PELG at the temperatures indicated. Time, $t$, and frequency, $f$, are interrelated by the Hamon approximation, $t=0.1 / f$.

with the parameters listed in Table I. The agreement between the experimental and calculated values seems excellent. This means that the molecular process responsible for the $\alpha$-relaxation and DC conduction loss should have a glass transition.

The glass transition temperature, $T_{\mathrm{g}}$, could be determined by two procedures. One procedure ${ }^{16}$ estimates it as the temperature where the experimental values for the shift factor begin to become lower than the WLF curve. The other procedure to determine $T_{\mathrm{g}}$ is as follows. The shift factor plotted against reciprocal absolute temperature can be approximately represented by two straight lines. The glass transition temperature is determined as the point of intersection of these straight lines. The values of $T_{\mathrm{g}}$ obtained by the two procedures agree well with each other. The glass 


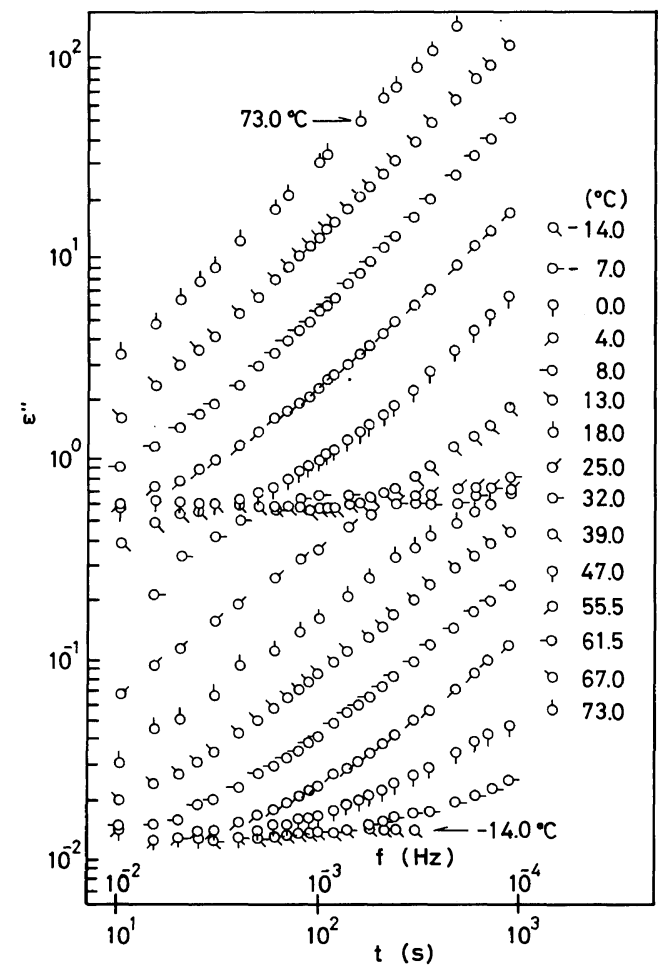

Figure 3. Time or frequency dependence of loss permittivity calculated from DC current data on PnPLG at the temperatures indicated. Time, $t$, and frequency, $f$, are interrelated by the Hamon approximation, $t=0.1 / f$.

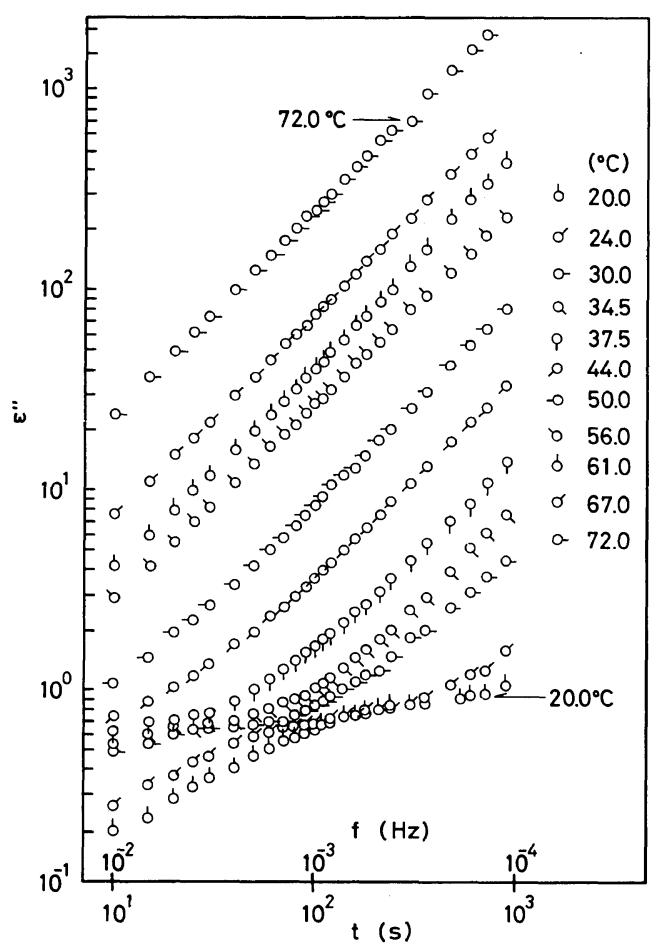

Figure 4. Time or frequency dependence of loss permittivity calculated from DC current data on PnBLG at the temperatures indicated. Time, $t$, and frequency, $f$, are interrelated by the Hamon approximation, $t=0.1 / f$.

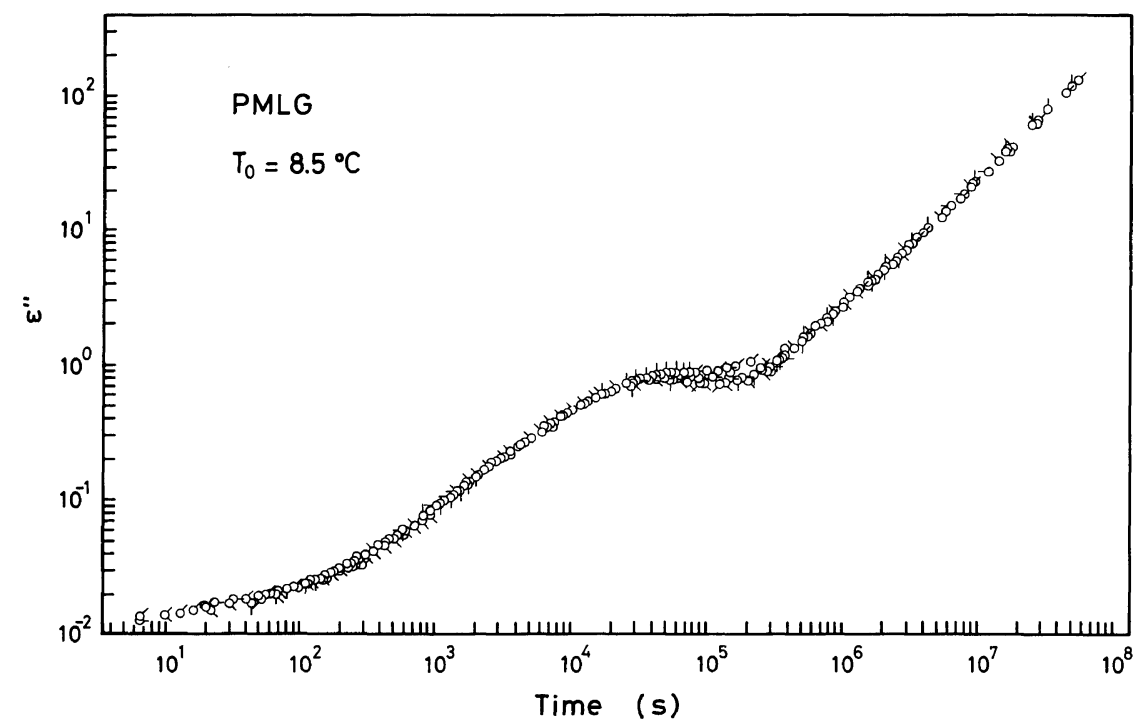

Figure 5. Loss permittivity master curve for PMLG reduced to $8.5^{\circ} \mathrm{C}$. Time, $t$, corresponds to frequency, $f$, through the Hamon approximation, $f=0.1 / t$. 


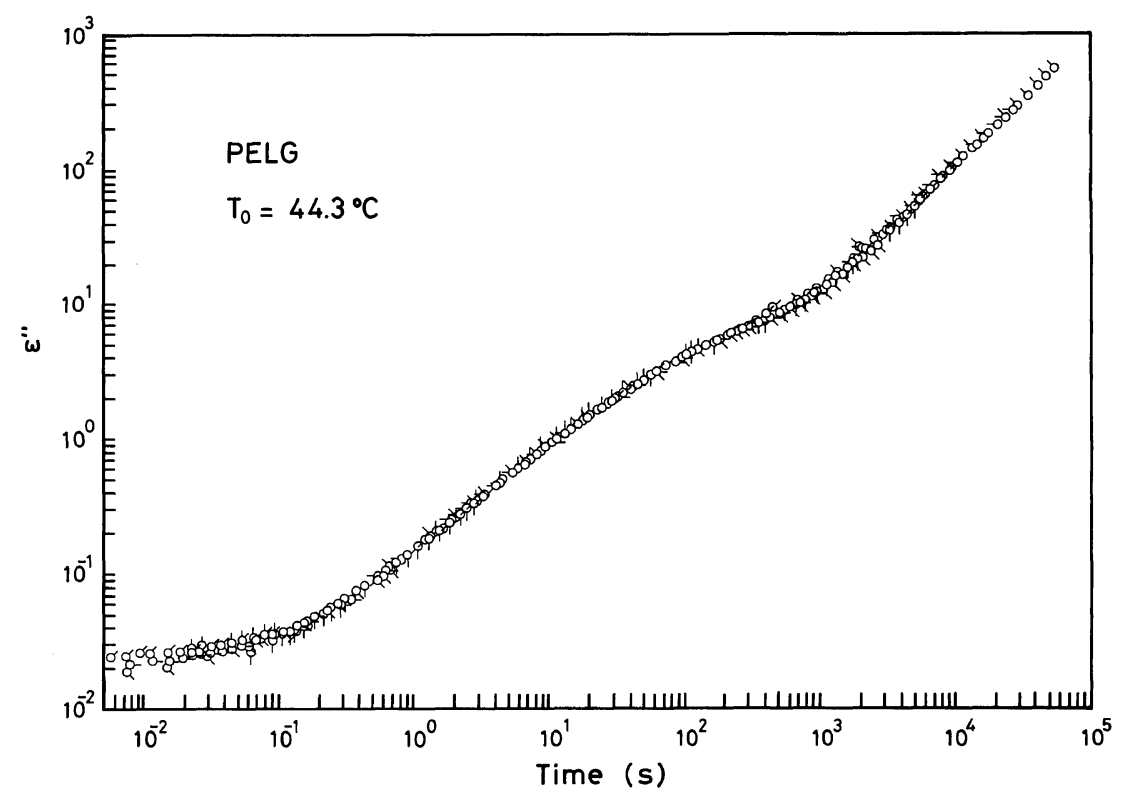

Figure 6. Loss permittivity master curve for PELG reduced to $44.3^{\circ} \mathrm{C}$. Time, $t$, corresponds to frequency, $f$, through the Hamon approximation, $f=0.1 / t$.

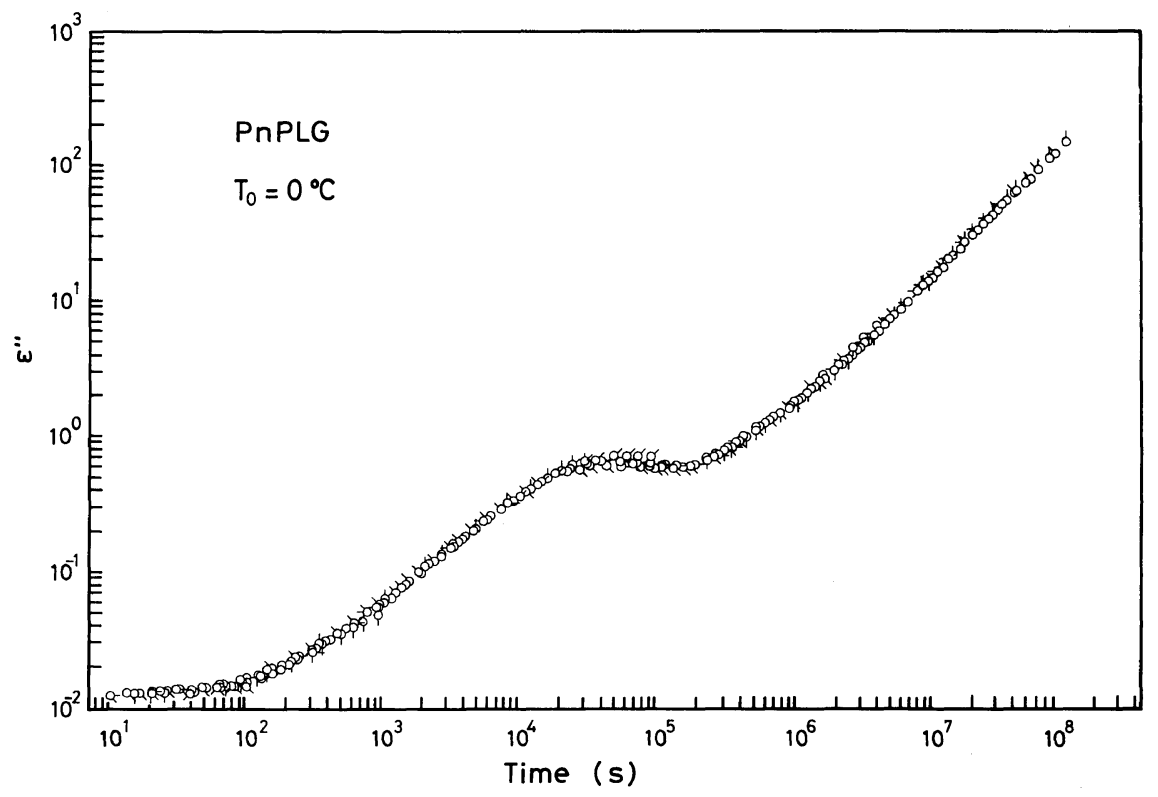

Figure 7. Loss permittivity master curve for PnPLG reduced to $0^{\circ} \mathrm{C}$. Time, $t$, corresponds to frequency, $f$, through the Hamon approximation, $f=0.1 / t$.

transition temperature for PnBLG cannot be determined owing to the lack of data.

The values of $T_{\mathrm{g}}$ and the WLF parameters referred to $T_{\mathrm{g}}, C_{1} \mathrm{~g}$, and $C_{2} \mathrm{~g}$, are given in Table
II. The value of $T_{\mathrm{g}}$ for PMLG is in good agreement with that determined from the data on temperature dependence of the DC conductivity. ${ }^{17}$ It seems that the glass transition 


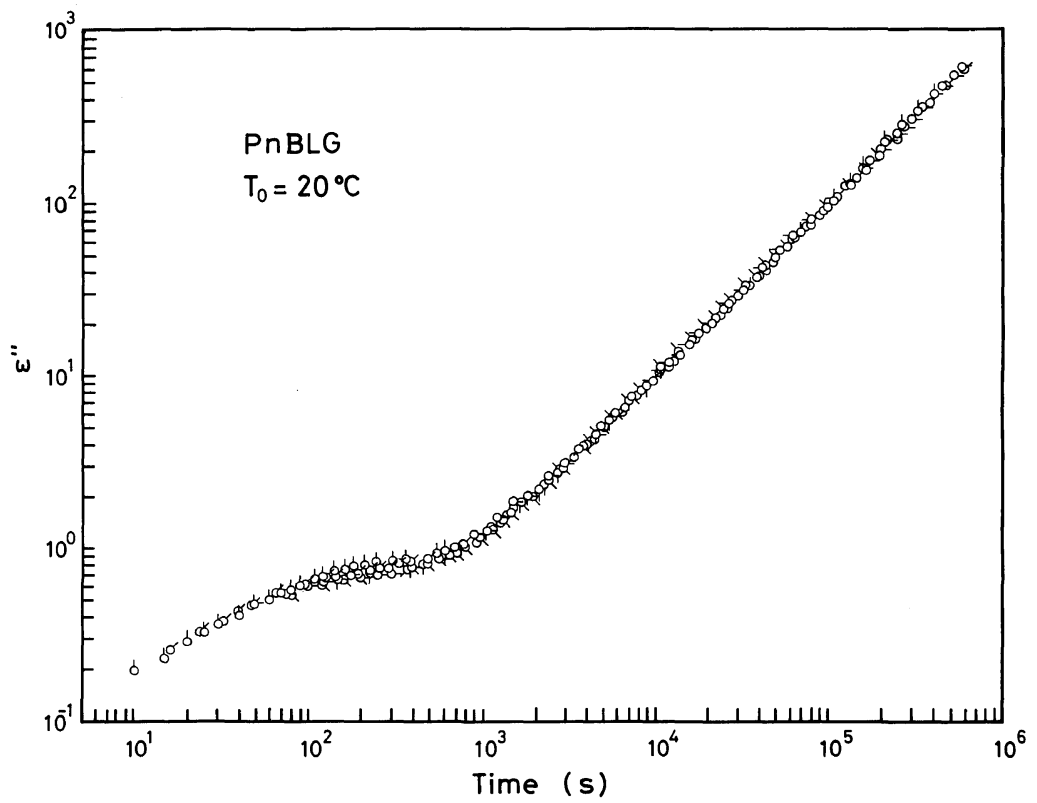

Figure 8. Loss permittivity master curve for PnBLG reduced to $20^{\circ} \mathrm{C}$. Time, $t$, corresponds to frequency, $f$, through the Hamon approximation, $f=0.1 / t$.
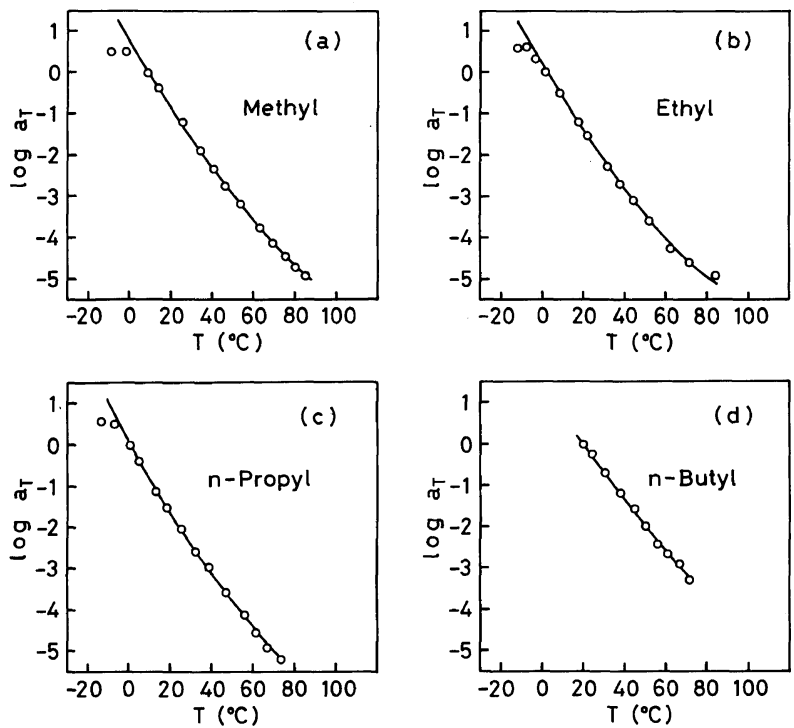

Figure 9. Temperature dependence of shift factors for (a) PMLG, (b) PELG, (c) PnPLG, and (d) PnBLG. Solid curve in each figure is calculated from the WLF equation with appropriate parameters.

temperature associated with the $\alpha$-relaxation decreases with the increase of the side-chain length as in the case of the poly $(n$-alkyl methacrylate)s, PnAMA's. According to the free-volume theory of the glass transition, $C_{1} \mathrm{~g}$ and $C_{2}{ }^{\mathrm{g}}$ are concerned with the fractional free volume at the glass transition temperature $f_{\mathrm{g}}$ and the thermal expansion coefficient of the free volume $\alpha_{\mathrm{f}}$ as follows, 
Table I. WLF constants at a reference temperature $T_{0}$ for each sample

\begin{tabular}{|c|c|c|c|}
\hline Sample & $\frac{T_{0}}{\mathrm{~K}}$ & $C_{1}{ }^{0}$ & $\frac{C_{2}{ }^{0}}{\mathrm{~K}}$ \\
\hline PMLG & 281.5 & 18.0 & 202 \\
\hline PELG & 274.8 & 17.5 & 197 \\
\hline PnPLG & 273.0 & 17.0 & 175 \\
\hline PnBLG & 293.0 & 15.0 & 188 \\
\hline
\end{tabular}

Table II. WLF constants at the glass transition temperature $T_{\mathrm{g}}$ and characteristics of free volume for each sample

\begin{tabular}{lcccccc}
\hline Sample & $\frac{T_{\mathrm{g}}}{\mathrm{K}}$ & $C_{1} \mathrm{~g}$ & $\frac{C_{2}{ }^{\mathrm{g}}}{\mathrm{K}}$ & $\frac{\alpha_{\mathrm{f}} \times 10^{4}}{\mathrm{deg}^{-1}}$ & $f_{\mathrm{g}}$ \\
\hline PMLG & 278 & 18.3 & 199 & & 1.1 & 0.024 \\
PELG & 269 & 18.0 & 192 & & 1.2 & 0.024 \\
PnPLG & 266 & 17.7 & 168 & & 1.4 & 0.025 \\
PnBLG & 265 & 17.6 & 160 & & 1.5 & 0.025 \\
\hline
\end{tabular}

$$
\begin{aligned}
& C_{1}^{\mathrm{g}}=B / 2.303 f_{\mathrm{g}} \\
& C_{2}^{\mathrm{g}}=f_{\mathrm{g}} / \alpha_{\mathrm{f}}
\end{aligned}
$$

where $B$ is a constant which is said to be nearly equal to unity.

As pointed out by Nakagawa and Ishida, ${ }^{18}$ the $C_{1}^{\mathrm{g}} \times C_{2}^{\mathrm{g}}$ vs. $C_{2}^{\mathrm{g}}$ plot for many polymers is represented by a straight line drawn through the origin and the point for "universal values." On the basis of the free-volume theory this means that the value of $f_{\mathrm{g}}$ is almost "universal" while the value of $\alpha_{\mathrm{f}}$ varies from sample to sample. As $f_{\mathrm{g}}$ is concerned with the practical limit of the time-scale to observe the volume equilibrium, this relation seems to be quite reasonable. Further, this fact suggests that the value of $B$ is also almost "universal." Therefore, this plot is useful to check the validity of the values of $C_{1}^{\mathrm{g}}$ and $C_{2}^{\mathrm{g}}$ determined experimentally.

In Figure 10 the WLF parameters for the samples used in the present study are shown to be quite consistent with the straight line men-

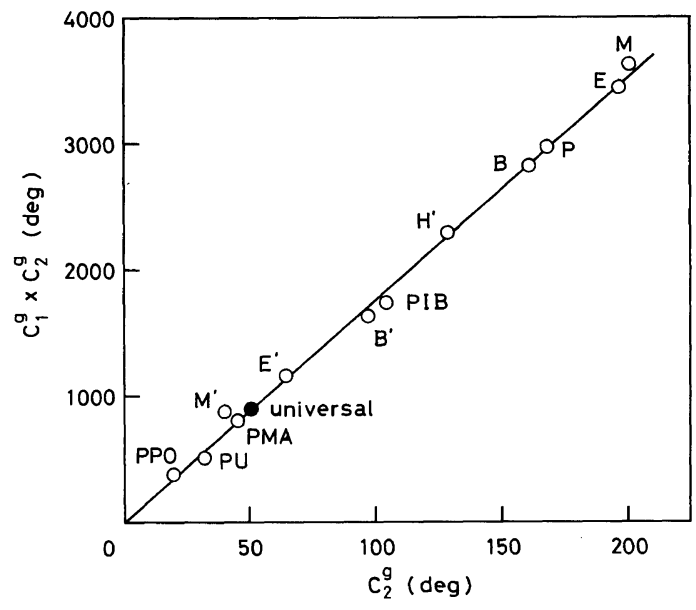

Figure 10. Relation between the WLF parameters at the glass transition temperature, $C_{1}{ }^{\mathrm{g}} \times C_{2}{ }^{\mathrm{g}}$ and $C_{2}{ }^{\mathrm{g}}$, for various polymers: $M, E, P$, and $B$ denote methyl, ethyl, $n$-propyl, and $n$-butyl glutamate polymers; $\mathbf{M}^{\prime}, \mathrm{E}^{\prime}, \mathbf{B}^{\prime}$, and $\mathrm{H}^{\prime}$ denote methyl, ethyl, $n$-butyl, and $n$-hexyl methacrylate polymers; PIB, PMA, PU, and PPO denote poly(isobutylene), poly(methyl acrylate), poly(urethane), and poly(propylene oxide); solid circle represents the "universal values".

tioned above. As for PnBLG, $\mathrm{C}_{2}^{\mathrm{g}}$ is estimated by the straight line and the value of $C_{1}^{\mathrm{o}} \times C_{2}^{\mathrm{o}}=C_{1}^{\mathrm{g}} \times C_{2}^{\mathrm{g}}$, since the glass transition temperature of this polymer has not been determined in the present study. The data on several polymers reported in the literature ${ }^{14}$ are also illustrated in the figure for comparison. The data on poly(methyl methacrylate) have been obtained by stress relaxation measurements made in our laboratory. ${ }^{19}$ The values of $\alpha_{\mathrm{f}}$ and $f_{\mathrm{g}}$ for (PnALG)s were calculated from eq 11 and 12 assuming that $B$ is equal to unity. The results are listed in Table II. It is remarkable that (PnALG)s have smaller values of $\alpha_{f}$ than those for (PnAMA)s and that the value of $\alpha_{f}$ for the former increases slightly with the increase of the sidechain length while that for the latter shows the opposite tendency. Such difference between the two series of polymers should be due to the difference in the structure and conformation of the main chain.

From the master curves given in Figures 5 


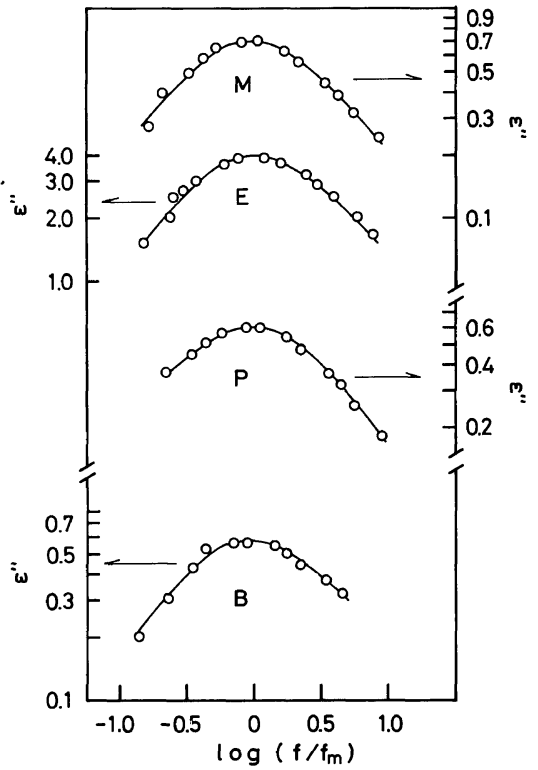

Figure 11. Loss permittivity plotted against logarithm of normalized frequency, $f / f_{\mathrm{m}}$. Here $f_{\mathrm{m}}$ denotes the frequency for the maximum of loss permittivity. M, E, P, and $\mathrm{B}$ denote methyl, ethyl, $n$-propyl, and $n$-butyl glutamate polymers, respectively.

8 the loss permittivity for the $\alpha$-relaxation in each sample can be obtained by subtracting the extrapolated portion of the straight line due to the contribution of the DC conduction. The Joss permittivity curves for the four samples thus obtained are shown in Figure 11 as a function of the normalized frequency. It should be noted that the shapes of the loss permittivity vs. frequency plot for these samples are the same and very sharp. The peak temperature observed at the same frequency decreases with the increase of the side-chain length as in the case of the glass transition temperature.

As a check of the validity of the master curve, the loss permittivity for the $\alpha$-relaxation in PELG was estimated without recourse to the method of reduced variables. From the original data on current as a function of time at $62^{\circ} \mathrm{C}$, the conduction current was estimated and subtracted to obtain the absorption current. The loss permittivity was calculated by

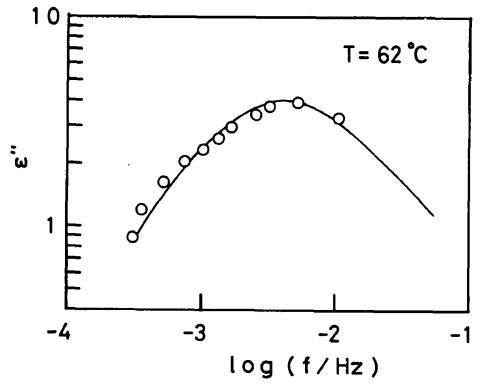

Figure 12. Loss permittivity at $62^{\circ} \mathrm{C}$ plotted against logarithm of frequency; open circles, for the values calculated directly from the data on DC current at $62^{\circ} \mathrm{C}$ by subtracting the conduction current and applying the Hamon approximation; solid curve, for the values obtained from the loss permittivity master curve reduced to $62^{\circ} \mathrm{C}$ which was composed of the curves calculated from DC current data at different temperatures using the Hamon approximation. The contribution from the conduction current was subtracted from the master curve.

applying the Hamon approximation to the data on the absorption current. The result is compared with that obtained from the master curve reduced to the same temperature as shown in Figure 12. The agreement seems quite satisfactory and consequently these procedures are consistent with each other. However, the former procedure of the data analysis using the master curve seems to be more appropriate, because the estimation of the DC conduction current in the original data used in the latter procedure is rather difficult.

The values of the electric conductivity $\sigma$ for (PnALG)s used in this study are estimated to be $10^{-15}-10^{-14} \Omega^{-1} \mathrm{~cm}^{-1}$ at $c a .60^{\circ} \mathrm{C}$ from the straight-line portions of the master curves. On the other hand, the values of $\sigma$ for PMLG and $\operatorname{poly}(\gamma$-benzyl L-glutamate) were reported to be of the order of $10^{-13}-10^{-15} \Omega^{-1} \mathrm{~cm}^{-1}$ in the temperature range $40-60^{\circ} \mathrm{C}^{17,20,21} \mathrm{As}$ the value of $\sigma$ seems to be very dependent on the sample preparation, the results obtained in the present study seem to be reasonable in the order of magnitude. Although the mechanism of the DC conduction in the polyglutamates is not yet clear, it is accepted by many investigators that the charge carriers are the ions 
contained in the samples.

The mode of molecular motion responsible for the $\alpha$-relaxation should be subject to the viscous resistance which is the same as that for the DC conduction loss, because the common shift factor can be applied to both processes. Furthermore, it should be noted that the mode of molecular motion for the $\alpha$-relaxation is frozen in a glassy state as a result of the increase in the viscous resistance obeying the WLF equation. The $\alpha$-relaxation cannot be caused by the motion of the side chain, since the relaxation process attributed to the sidechain motion in each sample is observed at temperatures much lower than the glass transition temperature for the $\alpha$-relaxation process as mentioned above and shown in the literature. $^{4,8,11}$ Consequently the $\alpha$-relaxation seems to be concerned with a motion of the main chain though the mode of the motion is not yet clear. The side-chain seems to effect an internal plasticization for the $\alpha$-process as suggested by the values of $T_{\mathrm{g}}$ given in Table II.

If this relaxation is observed only by dielectric measurements, it will be attributed to the mechanism proper to the dielectric behavior, such as the interfacial polarization, ${ }^{22}$ ionic relaxation $^{23}$ and so forth. However, it has been shown by many investigators that there is a relaxation (or relaxations) other than the sidechain relaxation at higher temperatures and lower frequencies. If the mechanical manifestation of the dielectric $\alpha$-relaxation studied here does exist, both the relaxations should be interpreted as due to the same molecular process. Therefore, a low-frequency mechanical behavior of the samples in the same temperature range as studied here seems to be necessary to discuss the molecular mechanism of the $\alpha$-relaxation in more detail. Such a study is now in progress in our laboratory.

\section{REFERENCES}

1. Y. Hashino, M. Yoshino, and K. Nagamatsu, Rep. Prog. Polym. Phys. Jpn., 9, 297 (1966).

2. Y. Yokomori, Y. Uematsu, and I. Uematsu, Rep. Prog. Polym. Phys. Jpn., 15, 633 (1972).

3. A. Tsutsumi, K. Hikichi, T. Takahashi, Y. Yamashita, M. Matsushima, M. Kanke, and M. Kaneko, J. Macromol. Sci., Phys., B8, 413 (1973).

4. A. Tanaka and Y. Ishida, J. Polym. Sci., Polym. Phys. Ed., 11, 1117 (1973).

5. A. L. Nguyen, B. T. Vu, and G. L. Wilkes, $J$. Macromol. Sci., Phys., B9, 367 (1974).

6. Y. Yamashita, A. Tsutsumi, K. Hikichi, and M. Kaneko, Polym. J., 8, 114 (1975).

7. N. Sasaki, H. Shimodata, Y. Yamashita, and K. Kikichi, Polym. J., 11, 983 (1979).

8. Y. Yamashita, K. Hikichi, and M. Kaneko, Polym. J., 12, 439 (1980).

9. T. Kajiyama, M. Kuroishi, and M. Takayanagi, $J$. Macromol. Sci., Phys., B11, 121 (1975).

10. T. Kajiyama, M. Kuroishi, and M. Takayanagi, $J$. Macromol. Sci., Phys., B11, 195 (1975).

11. J. Watanabe and I. Uematsu, Polym. J., 9, 195 (1977).

12. J. Watanabe, S. Sasaki, and I. Uematsu, Polym. J., 9., 451 (1977).

13. J. Watanabe, M. Naka, J. Watanabe, K. Watanabe, and I. Uematsu, Polym. J., 10, 569 (1978).

14. J. D. Ferry, "Viscoelastic Properties of Polymers," 2nd ed, Wiley, New York, N. Y., 1970.

15. B. V. Hamon, Proc. Inst. Electr. Eng., Part 4, 99, 151 (1952).

16. N. Saito, K. Okano, S. Iwayanagi, and T Hideshima, "Solid State Physics," Vol. 14, Seitz and Turnbull Ed., Academic Press, New York, N. Y., 1963.

17. S. Hirota, Kobunshi Ronbunshu, 36, 653 (1979).

18. K. Nakagawa and Y. Ishida, J. Polym. Sci., Polym. Phys. Ed., 11, 1503 (1973).

19. M. Kakizaki and T. Hideshima, unpublished data.

20. S. Hirota, J. Appl. Phys., 50, 3007 (1973).

21. K. Hikichi, A. Tsutsumi, T. Higuchi, and J. Saito, Polym. J., 10, 629 (1978).

22. R. W. Sillars, J. Instr. Electr. Eng., 80, 378 (1937).

23. S. Saito, S. Hirota, and H. Sasabe, Rep. Prog. Polym. Phys. Jpn., 17, 399 (1974). 